BULLETIN Bulletin hispanique

HISPANIQUE Université Michel de Montaigne Bordeaux

$118-2 \mid 2016$

Varia

\title{
El asesinato de Enrique IV de Francia y la publicística española del siglo XVII
}

Jesús M. Usunáriz

\section{(2) OpenEdition}

1 Journals

Edición electrónica

URL: http://journals.openedition.org/bulletinhispanique/4493

DOI: 10.4000/bulletinhispanique.4493

ISSN: 1775-3821

Editor

Presses universitaires de Bordeaux

Edición impresa

Fecha de publicación: 15 diciembre 2016

Paginación: 453-472

ISBN: 979-10-300-0125-9

ISSN: 0007-4640

Referencia electrónica

Jesús M. Usunáriz, «El asesinato de Enrique IV de Francia y la publicística española del siglo XVII », Bulletin hispanique [En línea], 118-2 | 2016, Publicado el 15 diciembre 2019, consultado el 28 diciembre 2019. URL : http://journals.openedition.org/bulletinhispanique/4493; DOI : 10.4000/

bulletinhispanique.4493 


\title{
El asesinato de Enrique IV de Francia y la publicística española del siglo XVII"
}

\author{
JESÚs M. UsunÁrIZ \\ Universidad de Navarra
}

Le régicide d'Henri IV de France (1610) a été condamné en Espagne à travers des relations de nouvelles, des poèmes, des chroniques et des traductions en contraste avec une attitude bien différente adoptée lors de l'assassinat d'Henri III (1589) et la justification du tyrannicide.

Mots-clés: Henri IV (1610), régicide, tyrannicide, chroniques et relations.

El regicidio de Enrique IV de Francia (1610) fue condenado en Espańa a través de folletos, poemas, crónicas y traducciones. Esto contrasta con la diferente actitud que se tuvo ante el asesinato de Enrique III (1589) y la justificación del tiranicidio.

Palabras clave: Enrique IV (1610), regicidio, tiranicidio, crónicas y relaciones de sucesos.

The regicide of Henry IV of France (1610) was condemned in Spain through pamphlets, poems, chronicles and translations. This contrasts with a different attitude adopted for the murder of Henry III (1589), and the justification of tyrannicide.

Keywords: Henry IV of France (1610), Regicide, Tyrannicide, Chronicles and Pamphlets.

\section{«SERENIDAD INSIGNE, HAZAÑA MEMORABLE!» VERSUS \\ «GRANDE TEMERIDAD Y LOCURA!»}

La noticia del asesinato el 1 de agosto de 1589 del rey Enrique III a manos del joven monje dominico Jacques Clément, fue recibida con gran alegría por los católicos franceses (Mousnier 1964: 198) y su muerte fue interpretada

* Este trabajo forma parte de los resultados del proyecto HAR2009-09987, Autoridad y poder en la España del Siglo de Oro: la representación del Imperio, la imagen de una politica exterior, subvencionado por el Ministerio de Ciencia e Innovación. 
por muchos -como lo hizo el embajador español en París- como un acto inspirado por Dios:

de manera que había llegado esta villa [París] a término que puedo decir a V.M. que ninguna que no se perdiese estuvo tan a pique dello como París, a quien Dios quiso hacer conoscer y a todos los católicos, el no tener olvidada su causa, enviándoles remedio para el convalescello de su mano y no pensando en entendimiento de los hombres ${ }^{1}$.

No obstante «el magnicidio -en palabras de Kamen- produjo un escalofrío en la espina dorsal de los españoles». Ningún teólogo español escribió nada en su defensa. El Consejo real, preocupado por la seguridad de Felipe II, instó al monarca a «no dejarse ver ni hablar de personas que no sean conocidas». Bien es verdad que como Enrique III había sido excomulgado por el Papa por el asesinato del duque y del cardenal de Guisa, no hubo ninguna ceremonia religiosa (1997: 295).

Habría que esperar a la muerte de Felipe II para que se publicaran trabajos en donde la muerte del rey francés en 1589 contara con cierta aprobación. En este sentido es conocido el capítulo VI del De Rege et regis institutione del Padre Mariana. Enrique III, sin descendencia, iba a dejar el reino a su cuñado Enrique de Navarra, "desde su más tierna edad, embebido en las más erróneas opiniones religiosas y había sido condenado por los pontífices y privado de su derecho de sucesión». Enrique III, además, había asesinado al duque de Guisa y a su hermano el cardenal y prendido a gran número de sus seguidores, por lo que fue excomulgado. Todo ello provocó la sublevación de numerosas ciudades, lideradas por París. Cuando el último de los Valois sitiaba la capital y estaba al punto de rendirse:

la audacia de un joven volvió a levantar los ánimos. Este joven se llamaba Jacobo Clemente y era natural de una aldea de Autun, conocida como Serbona, y estaba a la sazón estudiando teología en un colegio de los dominicos. Y como hubiera sabido por los teólogos que cursaba sus estudios que era lícito matar a un tirano, se hizo de varias cartas de los que pública o secretamente eran partidarios de Enrique, y sin tomar consejo de nadie partió hacia el campamento del rey con el propósito de matarlo el 31 de julio de 1589 [...] Después de cambiadas algunas palabras, cuando estuvo próximo al rey, so pretexto de entregarle en mano otras cartas, con un puñal envenenado que ocultaba en la misma mano, lo hirió en la vejiga. jSerenidad insigne, hazaña memorable! Traspasado el rey de dolor, hirió con el mismo puñal a su asesino en el pecho y en el ojo, al mismo tiempo que gritaba: “iAl traidor, al parricida!".

Los cortesanos, conmovidos por suceso tan inesperado, irrumpieron en la cámara del rey y acuchillaron con crueldad y fiereza a Clemente, que ya estaba postrado y exánime. Este no pronunció una sola palabra y más bien mostraba un semblante sereno, porque así evitaba otros tormentos que recelaba que sus fuerzas no podrían soportar. Y entre los golpes y heridas, su rostro revelaba la alegría de haber redimido con su sangre la libertad de sus conciudadanos y de su patria.

1. Carta del embajador español en París, Bernardino de Mendoza, a Felipe II, de 8 de agosto de 1589. (Vázquez de Prada 2004: 330). La cursiva es nuestra. 
Con la muerte del rey se ganó un nombre famoso en la historia, haciendo expiar una muerte con otra y ofreciendo aquella sangre real en holocausto del duque de Guisa, pérfidamente asesinado. Así murió Clemente, considerado por los más como una gloria eterna de Francia, cuando solo contaba veinticuatro años. Era modesto de ingenio y de cuerpo no muy robusto, pero algún impulso superior aumentó sus fuerzas y vigorizó su alma (Mariana 1981: 71-74)2.

El texto y, sobre todo, su tono, nos sirve muy bien para la comparación. Cuando veintiún años más tarde era asesinado Enrique IV, Mariana estaba lejos de compartir, en este caso, aquella velada admiración hacia el monje asesino -o tiranicida ${ }^{3}$. En efecto, en 1623, al publicarse una nueva edición de su Historia de España, en el «Sumario» redactado por el propio Mariana, da noticia del atentado de 1610:

En París, a 14 de mayo, un hombre muy particular y dicen maestro de escuela, por nombre Francisco Ravayllac, con un puñal mató al rey de Francia Enrique IV: ; Grande temeridad y locura! ${ }^{4}$.

¿Cuál fue la actitud en España ante el asesinato de Enrique IV? ¿Fue su muerte una aplicación de las tesis del derecho de resistencia y del tiranicidio de la que hablan los autores de la Escuela Jurídica Española?

\section{LA NOTICIA DEL ASESINATO EN ESPAÑA EN RELACIONES Y CRÓNICAS}

La noticia del asesinato de Enrique IV en aquel fatídico 14 de mayo de 1610 conmovió el corazón de los franceses y causó sensación en España -el "mayor caso que ha sucedido en nuestro tiempo en la Europa " - . De manera inmediata se publicaba en Valladolid -la licencia para su impresión se dio el 7 de junio- un romance compuesto por un tal Diego Vasurro (Bazzurro), la Relación verdadera, sacada de una carta de las que a Su Majestad enviaron, en que trata la muerte lastimosa del Quarto rey don Enrique de Francia y la jura de la reina y delfin, su hijo, despues de este triste suceso, y del aprieto en que se vio el embajador de España, con los sentimientos que los católicos reyes de España hicieron ${ }^{6}$. En sus versos relata la aflicción causada en España por la muerte del rey:

2. La cursiva es nuestra.

3. Si bien precisa Mariana en ese mismo capítulo, su tesis de porqué y por quién se puede matar al tirano, creo que es indudable que el jesuita profesaba si no admiración, sí respeto, hacia la figura del monje dominico, a pesar de los criterios de Centenera Sánchez-Seco (2004).

4. Citado en Ballesteros Gaibrois (1943: 230).

5. Así lo afirma Gil González Dávila cuando aprueba la publicación de la obra de Mathieu, Historia de la muerte de Enrico el Grande, Cuarto rey de Francia deste nombre, escrita en francés por Pedro Mateo, Madrid, Diego Flamenco, 1625, traducida por Pablo Mártir Rizo en 1625.

6. Puede consultarse la versión digitalizada de esta y otras relaciones que se citan en el "Catálogo y Biblioteca Digital de Relaciones de Sucesos (siglos XVI-XVIII)» del Grupo de Investigación sobre Relaciones de Sucesos (S. XVI-XVIII) de la Universidade da Coruña o en la página que recoge las «Relaciones de Sucesos» de la Biblioteca de la Universidad de Sevilla. 


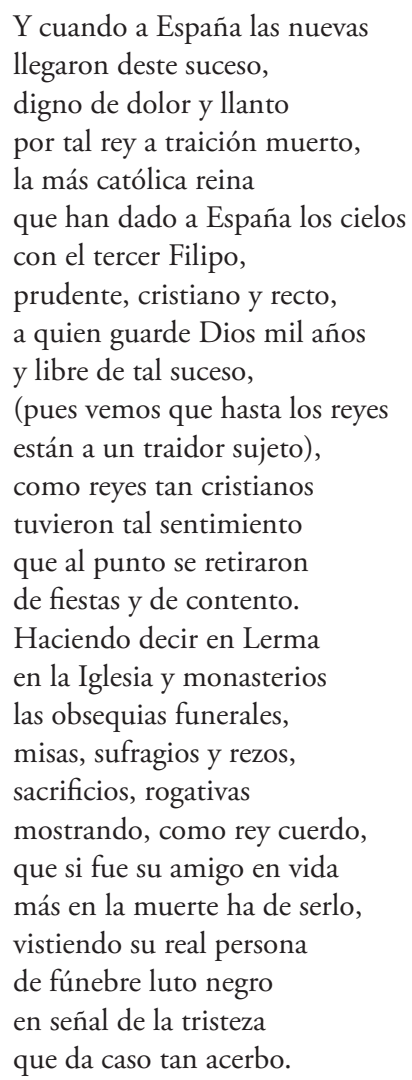

Hechos similares - de manera muy sucinta- se describen en la Verissima relacion de las fiestas que se hizieron en la coronacion de la Reyna de Francia en Paris y orden con que todo se hizo. Assi mismo se dà quenta de la muerte del Rey de Francia, como sucedió, y en que forma, publicada en Sevilla en 1610. También sevillana es la Relacion verdadera del solenissimo Acompanamiento y particulares Ceremonias del entierro de Enrique Quarto, Rey de Francia, que duro tres dias desde veynte y nueve de Iunio hasta primero de Iulio que quedo el Cuerpo en San Dionys. Y vltimamente la aclamacion del Pueblo al nuevo Rey Luys Tercero deste nombre, en donde se describe con gran lujo de detalles la comitiva del entierro.

Pocos años después, Cabrera de Córdoba en sus Relaciones de las cosas sucedidas en la corte de España desde 1599 hasta 1614, daba cuenta de la llegada a la corte de la carta del embajador español en París, don Ínigo de Cárdenas a Lerma, en donde daba noticia de la muerte y asesinato del rey Enrique IV:

la cual causó tanta admiración, así por el suceso tan desastrado de ella como no esperado en esta ocasión, si no se juntara con ello haberlo sabido el embajador de Francia dos días antes, aunque lo tuvo secreto y no lo publicó hasta que vino la nueva de Lerma, juntamente con la del parto de la reina. Y fue causa para que no se hiciese demostración de luminarias, ni regocijo, como se acostumbra. Y luego S.M. se puso luto y los de su Cámara, y se envió orden para que hiciesen lo mesmo los señores y títulos, y se envió a llamar la Capilla Real para las honras que se habrán de hacer en la iglesia mayor de Lerma, para lo cual se hacía el túmulo muy apriesa, porque quieren 
hacerlas un día de la semana que viene, antes del bautismo de la Infanta, la cual dicen se llamará dońa Margarita. Y envían al duque de Feria a Francia a dar el pésame de la muerte del rey (1857: 406-407) ${ }^{7}$.

En la Historia de Felipe III de Matías Novoa la recepción de la noticia es narrada de forma similar. El rey, que se encontraba por entonces en la villa de Lerma para celebrar el nacimiento de la infanta,

quedó suspenso y todo su palacio, sintiendo con admiración el suceso fatal de Enrique. Con este sentimiento hizo levantar un solemne túmulo en la iglesia mayor de aquella villa, donde cubierto de luto el rey y toda su Casa, se celebraron las honras. (Novoa 1875 I: 431)

Muy pronto se traducen también algunas relaciones francesas, como la que se publica en Zaragoza, en 1610, titulada Discurso lamentable sobre el atrevimiento y parrecidio cometido en la persona del rey Enrique Cuarto, de gloriosa memoria, rey de Francia y de Navarra, de Roberto Duport, en donde más que dar cuenta del asesinato, se aboga por la transición tranquila y por la unidad de Francia y de los franceses. Y en 1625 se publicaba en Madrid la Historia de la muerte de Enrico el Grande, traducción de Pablo Mártir Rizo, de la obra del francés Pierre Mathieu que salió a la luz en $1611^{8}$, que serviría de base para otros autores españoles, como Novoa o González Dávila, al narrar e interpretar los hechos.

Al mismo tiempo no son pocos los poemas compuestos para lamentar como hace Quevedo- el asesinato «del mayor rey que vio jamás la Galia». Así Quevedo escribiría al menos cinco poemas; uno el conde de Villamediana, otro Góngora, otro Lope de Vega, un madrigal Pedro de Soto de Vargas y hubo más (Jauralde 1999: 230-234).

Enrique IV, el otrora enemigo hereje de la Monarquía hispánica, no recibe, a la hora de su muerte, sino muestras de admiración y respeto en "este caso lastimoso». Y especialmente por su valor militar: «tan valeroso en las armas»",

7. Y describe más adelante: «Celebráronse las exequias del Rey de Francia en la iglesia mayor de Lerma a los 8 y 9 del pasado [se refiere a junio] con mucha solemnidad y cumplimiento, hallándose S.M. presente. Para lo cual fueron de aquí los cantores de la Capilla Real y algunos capellanes que asistieron al oficio, y todos los seńores, títulos y caballeros que se hallaban allí. Y predicó el arzobispo de Burgos, que dicen lo hizo muy bien, y la reina nuestra señora no pudo estar presente por no haberse levantado de la convalescencia del parto». p.468. Sobre la embajada del duque de Feria a París Vid. González Dávila (1998: 138).

El mismo autor narra cómo fue el duque de Lerma el encargado de comunicar al rey la muerte del francés: «Nuestro rey la recibió en la villa de Lerma y se la dio a la una de la noche, estando acostado, el duque de Lerma, que llegándose a la cortina le dijo: «Señor, de París ha llegado un correo con la muerte del rey». Respondió con algunas palabras compasivas y con decir: «Dios le haya dado el cielo». Y a la mañana mandó se le hiciesen honras y funerales y se le dijesen misas por el descanso perpetuo de su alma». (138).

8. Histoire de la mort déplorable de Henry IIII, Roy de France et de Navarre: ensemble un poème, un panégéryque et un discours funèbre dressé à sa mémoire immortelle, Paris, Guillemot et Thiboust, 1611. La versión española: Historia de la muerte de Enrico el Grande, Cuarto rey de Francia deste nombre, escrita en francés por Pedro Mateo, Madrid, Diego Flamenco, 1625.

9. Relación verdadera. Vid. también García Bernal (2008 1: 1008). 
que lo convierte en el deseado enemigo a batir por su valor. Novoa exalta cómo su muerte: «sintiéronla los españoles porque querían más pelear con él, antes que con otro capitán, porque les sabía dar fama y acrecentar valor su osadía (Novoa 1875 I: 430) ${ }^{10}$. El que más se extiende en ello será Quevedo en sonetos como «Inscripción al túmulo del rey de Francia Enrique IV», en su «Memoria fúnebre del mismo rey Enrique IV» o en el «Epitafio para el mismo» (Quevedo 1952: 520-521) $)^{11}$.

Pero su muerte también es vista con alivio. Francia que, desde 1598, no deseaba ni podía permitirse entrar en un conflicto abierto con España, no por ello dejó de promover «guerras floridas», «un combate "pacífico" por la hegemonía», de intimidación y prestigio, de objetivos limitados, cortas, pero que suponían un desgaste para la Monarquía hispánica, gracias a las cuales Enrique IV quería servir de contrapeso a la casa de Austria. Por su parte y para lograr sus objetivos, España forzó que su diplomacia hiciera lo posible por evitar crisis generalizadas. De esta forma, el asesinato del rey francés en 1610-en el momento en que estaba a punto de estallar la crisis por la sucesión de los ducados de Juliers y Clèves, en lo que prometía ser una guerra abierta entre Francia, España, el Imperio y los príncipes protestantes alemanes-, dio lugar a un período de inestabilidad que beneficiaría notablemente los intereses españoles.

Hase tenido por caso prodigioso y encaminado del cielo -escribe Cabrera Córdoba-, la nueva del rey de Francia, habiendo sucedido en tiempo que en todas partes se apercibían las armas, esperando adonde iría a dar el golpe con el ejército que tenía levantado, aunque la voz sonaba era para socorrer al de Brandemburg en la empresa de Cleves, y aquí se apresuraba la prevención de las lanzas con que sirven los señores, títulos, prelados y comendadores, y asimesmo a la milicia y batallón de los lugares del reino, y con este suceso ha parado todo. Plegue a Dios sea causa de mucha paz en la Cristiandad (1857: 407) $)^{12}$.

Como narra Novoa, con la «nueva de tan estupendo caso», «los enemigos - de España, se entiende- temblaron, viendo desbaratados sus intentos y frustrada y deshecha la liga, que tan amenazada tenía las Provincias -Flandes- como si España no estuviera enseñada a romper y consumir ejércitos y hollar capitanes y arrojar reyes no menos belicosos que Enrique, ni de menos nombre y fama» (1875 I: 430).

$\mathrm{Y}$ en su muerte no falta tampoco la nota providencialista. Tanto por las señales y presagios (Mousnier 1964: 21 y ss) ${ }^{13}$ que anunciaron su muerte, y que

10. Admiración, al parecer compartida, pues según el autor Enrique IV «no se hartaba de alabarlos» y decía «los quería más para amigos que enemigos»(Novoa 1875 I: 430).

11. Esta alabanza hacia el monarca guerrero entraba en contraste con el rey español, y suponía una crítica -según interpreta Jauralde-a la política exterior hispana (Jauralde 1999: 231).

12. Y González Dávila: «Así acabó aquel rey. Sus armas y banderas, con el golpe de su muerte, no pasaron adelante, y se deshicieron como nube ligera llevada de un fuerte viento» (1998: 138).

13. En la línea marcada por Plutarco y la narración del asesinato de Julio César. Vid. Martinengo (2002-2003). 
comparten autores como Novoa o González Dávila ${ }^{14}$, siguiendo la estela del francés Mathieu, como ver en el suceso la mano última de Dios en los designios humanos:

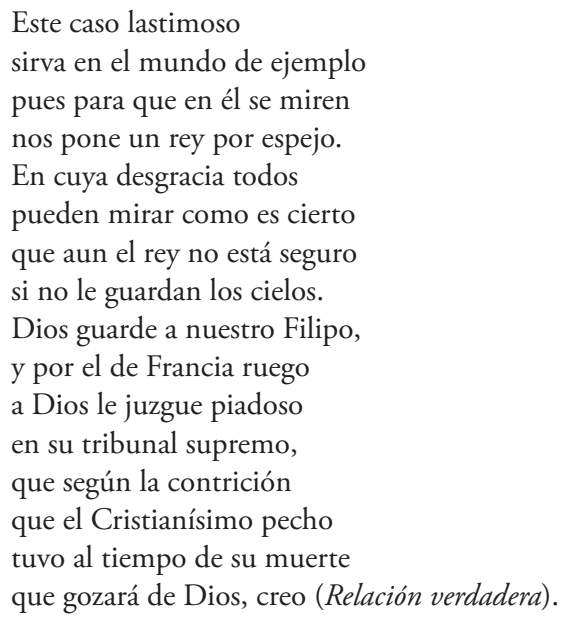

A diferencia del rey, Ravaillac es objeto de desprecio. «hombre de baja suerte» (Verísima relación), «mal hombre, indigno de nombrarse» (Carrillo 1634: 490r), «de estado humilde y plebeyo» y loco: «hombre tenido, en la opinión de los que le conocían, por perdido y desbaratado» (Novoa 1875 I: 428) ${ }^{15}$, en donde no falta la atribución de su asesina tropelía a la diabólica inspiración

14. También otros autores como Guadalajara y Javier (1630: 164), narran las profecías de varios astrólogos, y visiones de algunos caballeros de la corte francesa. Céspedes y Meneses al narrar las negociaciones del matrimonio del príncipe Felipe con Isabel, la hija de Enrique IV, hace alusión a la mala suerte que perseguía a los monarcas llamados «Enrique», aunque se muestra más reticente a cualquier tipo de superstición. Para el autor Enrique IV fue «aquel a quien ha dado Francia renombre y título de Magno», "aquel que supo abrir camino para adornarse de la púrpura contra las fuerzas superiores y más pujantes de la tierra», «aquel que entre los triunfos de sus hazañas, rodeado de ejércitos y de disinios en el concurso de su reino y regocijo de su corte, se vio atrozmente perecer a manos de un hombre miserable (loco escribiente de Angulema), sino decimos de los cielos, que nunca fueron más durables las prosperidades desta vida, ni hay cosa en ella tan estable que no padezca corrupción [...] Este desastre confirmó en su opinión a algunos hombre que tienen para España y Francia el nombre de Enrique por infausto. Seis ha observado la malicia o la curiosidad de ambas naciones, muertos a hierro o con violencia. A Enrique primero de Castilla, una piedra tirada sin disinio le hizo morir, como al segundo los borceguíes venenados que le envió el rey de Granada, y al que llamaron el enfermo, las drogas de un médico judío. En Francia Enrique de Valois ocasionó también su muerte, justando con Mons. de Mongomeri, caballero escocés. Todos sus hijos tuvieron fines desdichados y a Enrique Tercero que fue el uno con alto espíritu le dio de puñaladas otro fraile y al Cuarto y Magno, el que advertimos. Casos son estos y secretos que Dios reserva para sí, toda supersitición y sutileza, trabajo en vano investigándolos, aunque sin duda gran recuerdo y sí amarguísima dotrina muy necesaria a los monarcas, para que entiendan y conozcan no que tan solo son humanos, sino sujetos y rendidos a las miserias más vulgares». (1631: 4)

15. Góngora lo califica también despectivamente de plebeyo:

El Cuarto Enrico yace mal herido

Y peor muerto de plebeya mano (1972: 211). 
-«no tenía otro instigador que su locura y el demonio» (Novoa 1875 I: 432) ${ }^{16}$. Pero todos coinciden en un adjetivo: traidor: «un mal vasallo, traidor a su rey y patria» (González Dávila 1998: 137), merecedor del crudelísimo castigo al que fue sometido ${ }^{17}$.

\section{La EXCULPACión de EsPaña}

Buena parte de los escritos pretendieron, desde el primer momento, la exculpación de España ante las sospechas, inmediatas, de su complicidad en la muerte del Borbón o en su instigación ${ }^{18}$.

Luego que esto sucedió se alborotó París notablemente, poniéndose en armas y con una confusión terrible de haber corrido alguna palabra que era español el que le había herido y de la inquietud de la mesma gente, comenzó a acudir golpe de pueblo a casa de don Inigo de Cárdenas, embajador de España.

Algo que solo pudo frenar la reina viuda, que protegió la casa del embajador ${ }^{19}$. En el romance tercero de la citada Relación verdadera, titulado «Del rebelión que se levantó contra don Ińigo de Cárdenas y Zapata, embajador de España», se describe el ambiente hostil que se respiraba en la capital parisina, con la gente «pidiendo a voces venganza» mientras cercaba la posada del embajador de España,

$$
\begin{aligned}
& \text { Levantando por París } \\
& \text { en pública voz y fama } \\
& \text { que era español el que había } \\
& \text { dado al rey de puñaladas. }
\end{aligned}
$$

Fue la reina, sin embargo quien puso al embajador bajo su protección. El interrogatorio y tortura del asesino revela la cruel verdad:

$$
\begin{aligned}
& \text { Y poniéndole en el potro } \\
& \text { sin que le aprieten declara } \\
& \text { ser francés de Normandía } \\
& \text { cosa que a todos espanta }{ }^{20} .
\end{aligned}
$$

16. También de traidor es calificado por Guadalajara y Javier y lo describe como «monstruo incitado del demonio, sin respeto de la sacra unción con que honra Dios a los reyes, sus lugartenientes» (1630: 163).

17. Y que es descrito con detalle por la mayoría como Novoa (1875 I: 431), González Dávila (1998: 137) o Guadalajara y Javier (1630: 165).

18. Sobre estos rumores en Francia, Mousnier (1964: 27 y ss). Courouau reproduce un epitafio a Enrique escrito por Jean de Garros en castellano, que consideraba al traidor y asesino «Francés de nation, Spañol pour suerte» (2004: 633).

19. Verissima relacion.

20. En la Verissima relacion, se recuerdan los mismos hechos. El rey, herido gravemente murió al cabo de una hora "sin poderse confesar, aunque le absolvió el cardenal de Surdi, por señales que hizo de contrición». El asesino, francés, de Angulema, había sido detenido, y solo se sabía que había confesado "que el diablo se lo hizo hacer. Halláronle en el pecho unos caracteres de cosas de hechicerías y ha confesado que había algunos días que andaba tras hacerlo». Poco 
Y declara el reo:

Sabréis que ha más de tres años
que con diabólicas trazas
me ha persuadido el demonio
a que mate al rey de Francia.
Mil veces me resistía
pero su infernal pujanza
es a tal que por momentos
para hacerlo me incitaba.
No pienses reina y señora
que de naciones contrarias
me han mandado que lo hiciese
que quien lo piensa, se engaña.
Y el embajador que tienen,
cercado con tantas armas
está señora inocente
que jamás le hablé palabra.
Yo solo el autor he sido,
nadie presuma que España
pudiera mandar hacer
tal traición ni imaginarla.
Aquesto es verdad, franceses
que sin más razón ni causa
que mandármelo el demonio
quité de su cuerpo el alma ${ }^{21}$.

¿Es de extrañar esta rápida salida para acallar la responsabilidad española en el asesinato? No lo creo; no solo por la vieja y permanente rivalidad entre ambas monarquías, sino también por la conciencia existente en Francia de la procedencia de muchas de estas teorías. Así, cuando Suárez publicó su Defensio fidei, la condena en Inglaterra y Francia estaba relacionada con que a las tesis que contenía, entre ellas las del tiranicidio "para esto llaman "doctrina de España" a lo que escribe el P. Suárez» ${ }^{22}$. Marcos de Guadalajara señala que Ravaillac confesó haberse fundado en las tesis de Mariana:

El mismo día del castigo de Ravaillac, porque el reo en todas sus respuestas a las preguntas que el arzobispo de Aix y Pedro Corseteau y muchos otros le hicieron durante su prisión sobre su parricidio, se ayudaba con sutileza de las máximas de algún gran doctor, que en un libro que escribe, De Regis institutione, enseña ser lícito matar al tirano. Y esta dotrina fue condenada y su libro quemado en la plaza de París. Porque se disputaban muchos estudiantes desta proposición, prendieron algunos. (Guadalajara y Javier 1630: 65)

después «se alborotó París» y "con una confusión terrible de haber corrido alguna palabra que era español el que le había herido, y de la inquietud de la mesma gente, comenzó a acudir golpe de pueblo a casa de don Inigo de Cárdenas, embajador de España». Aunque finalmente fue protegido por la reina. También en González Dávila (1998: 137).

21. La cursiva es nuestra.

22. Citado por Scorraille (1917: c. 4, 15). 


\section{¿UN CAMBIO DE ACTITUD HACIA EL TIRANICIDIO?}

Asombro, alivio, desprecio del asesino, solidaridad hacia la monarquía francesa..., la actitud hacia la muerte del rey galo distaba mucho de la opinión que dos décadas antes había suscitado el asesinato de Enrique III. ¿Era el síntoma de un cambio en las actitudes hacia el tiranicidio?

Conviene ahora hacer un repaso sucinto de estas teorías en la España del siglo XVI y de comienzos del Seiscientos ${ }^{23}$. Dentro de la Escuela Jurídica Española debe destacarse la posición de aquellos que apoyados en la «defensa de los derechos naturales y la concepción pactista subyacente», defendían un poder limitado, tal y como señala Martínez Tapia. Es decir, quienes consideraban que la única autoridad legítima era la que dimanaba del pueblo, titular natural de la misma, y que la trasladaba mediante un pacto o contrato al soberano. «El fundamento jurídico de todo poder público es, por tanto, la sumisión voluntaria, bajo forma contractual, de la comunidad, esto es, el pactum subjectionis o contrato político». Para los autores este contrato se denomina de diferentes formas: "concesión» (Vitoria, Azpilcueta, Suárez), «mandato» (Vázquez, Mariana), «uso» (Azpilcueta), «representación» y «donación» (Suárez).

De acuerdo con ello el monarca no puede ser legibus solutus, sino limitado por el Derecho en cuanto libre y espontánea expresión del pueblo -es decir, legibus alligatusy su principal función será la de impartir justicia sometiéndose a ese mismo Derecho. Por eso el príncipe había de comprometerse a cumplir las leyes y costumbres del reino y en el respeto a ese ordenamiento, es decir, a los fueros y costumbres del país, se fundamentaba la sujeción misma de los súbditos, justificándose, en caso contrario la resistencia. (Martínez Tapia 1998: 51-52)

Es cierto que buena parte de las ideas "pactistas», "constitucionalistas» están vinculadas al pensamiento medieval y sus tesis contractualistas y de exigencia de limitación del poder al Derecho (Martínez Tapia 1998: 50). Pero no sería hasta el siglo XVI cuando la polémica se avivó gracias, fundamentalmente, a dos razones: primera, el más que evidente fortalecimiento del Estado moderno y la necesidad, para algunos autores, de poner límites a la autoridad del poder real; segunda, la ruptura religiosa, que dio lugar a luchas internas y externas, y puso de actualidad el papel de los monarcas en la lucha contra la herejía, y el debate en torno al derecho de resistencia y, más aún, sobre el concepto y el ejercicio de la soberanía. A su vez, se hace imprescindible asomarnos al análisis del tiranicidio pues fue parte esencial en la cultura política europea de la Edad Moderna (Ranum 1980: 63) ${ }^{24}$. Es cierto que no fueron numerosos los casos, pero sí, que su impacto los mantuvo presentes en la memoria de la población durante varias generaciones (Ranum 1980: 64).

23. Un resumen en Usunáriz (2008).

24. También Bercé y Fasano 1996: 46. 


\section{La soberanía y la naturaleza del poder}

Para analizar la actitud de la Escuela Jurídica Española, hay que partir de su concepto de cuál es el origen de la soberanía, tras lo cual se establecen los límites del poder y los mecanismos para la defensa de los pilares que sostienen la comunidad política.

Para Azpilcueta, como para el resto de los miembros de la Escuela «la potestad [es] dada por Dios, naturalmente, de modo inmediato a la comunidad de los mortales para que vivan bien y dichosamente, conforme a la razón natural» (Bullón y Fernández 1936: 67). Es decir, el poder, que emana de Dios, reside en la comunidad que lo entrega al gobernante para que lo ejerza en beneficio de la misma. Y así lo sostendrá la mayoría con la excepción de Vitoria que se muestra más ambiguo ${ }^{25}$. Martín de Azpilcueta, en el año 1528, en una lección impartida en Salamanca el 29 de junio lo expresó así:

El reino no es del rey, sino de la comunidad, y la misma potestad regia no pertenece por derecho natural al rey, sino a la comunidad, la cual, por lo tanto, no puede enteramente desprenderse de ella (Bullón y Fernández 1936: 36-37) ${ }^{26}$.

Doctrina que sería adoptada por todos los pensadores espańoles del momento. El padre Bartolomé de las Casas sostuvo que,

el poder de soberanía procede inmediatamente del pueblo. Y es el pueblo la causa efectiva de los reyes o príncipes y de todos los gobernantes, si es que tuvieron un comienzo justo ${ }^{27}$. [Y sigue]: Luego, si el pueblo fue la causa efectiva o eficiente y también la causa final de los reyes y príncipes, de forma que tuvieron su origen en el pueblo fue la causa efectiva o eficiente y también la causa final de los reyes y príncipes, de forma que tuvieron su origen en el pueblo a través de elecciones libres... parece que cuando un pueblo eligió sus príncipes o su rey no perdió su propia libertad, ni renunció o concedió poder de gravarle, coaccionarle, ordenar o imponerle cargas en perjuicio de todo el pueblo o comunidad política ${ }^{28}$.

Francisco Suárez, en su obra Defensio fidei catholicae adversus anglicanae sectae errores, frente a las tesis de Jacobo I, defendía:

...según el orden natural de las cosas, ningún rey o monarca tiene ni ha tenido inmediatamente de Dios el principado político, sino mediante la voluntad y la institución humanas ${ }^{29}$.

Conforme al principio de la superioridad de la república sobre el rey, es la comunidad la auténtica titular del poder. Bien es verdad que se trataría de una

25. Para Vitoria, «Los reyes por derecho divino y natural tienen el poder y no lo reciben de la misma república, es decir de los hombres». Citado por Brufau (1960: 152).

26. Cita de Azpilcueta de su Relectio cap. Novit de Iudiciis non minus sublimis, quam celebris, pronunciata ann. 1548 ...

27. Las Casas, De Regia Potestate, IV, 1 y IV.3. Citado por Martínez Morán (1991: 429-430).

28. Las Casas, De Regia Potestate, IV.3. Citado por Martínez Morán (1991: 430).

29. Ibid., p. 45. Defensio Fidei...Libro III, cap. II. 
soberanía dual, compartida por el príncipe -potestas in actu-, y la república -potestas in habitu o radical-. O si se quiere, como Vitoria, mientras que la comunidad conserva las competencias de la sustancia del poder, la potestas, entrega al príncipe la auctoritas. En consecuencia, el poder que se transfiere al príncipe, nunca es absoluto, sino limitado.

¿Cuáles serían estos límites? Siguiendo el lúcido trabajo de Martínez Tapia en primer lugar habría que hablar de los límites jurídicos del poder, que serían: el Derecho Natural, los derechos subjetivos, las leyes fundamentales, el Derecho positivo, el Derecho privado, las instituciones y el Derecho de gentes. En segundo lugar, los límites teleológicos.

¿Por qué el Derecho natural? Para los miembros de la escuela, la soberanía del rey, siempre debía estar sometida al Derecho natural, es decir, nunca podía mandar nada que fuese injusto ${ }^{30}$. Aquí se integrarían, por ejemplo, el derecho a la vida, la libertad natural, la libertad de pensamiento, un conjunto de derechos fundamentados en la dignidad del hombre, que debían ser respetados por la autoridad, en lo que sería un límite ético-jurídico de su poder (Martínez Tapia 1998: 60). ¿Qué son los derechos subjetivos? Sería el conjunto de derechos individuales y colectivos, establecidos de manera contractual entre la comunidad y el rey, y que eran un límite jurídico para el ejercicio del poder real. Las leyes fundamentales, como concepto surgió como la necesidad de distinguir, ya en la Baja Edad Media, entre las leyes ordinarias, o mandatos circunstanciales del príncipe y la ley fundamental y primera, por la que la monarquía o la autoridad alcanzaba legitimidad (60). Uno de los que más precisa su concepto sería Mariana. Éste distingue "entre leyes dadas por el príncipe y leyes que proceden de la comunidad o "leyes del reino", cuya autoridad y poder es superior al príncipe, razón por la que éste no puede tocarlas». ¿Cuáles serían estas? Dice Mariana:

Muchas leyes, además, no son dadas por los príncipes, sino establecidas por toda la comunidad, cuya autoridad para mandar y para prohibir es mayor que la del príncipe [...]. Y a tales leyes, a nuestro juicio, no sólo el príncipe debe obedecerlas, sino que no puede alterarlas sin el expreso consentimiento de las Cortes, debiéndose contar entre aquéllas las referentes a la sucesión real, a la religión y a la imposición de tributos. (Mariana 1981: 108-109)

El hecho de que sea necesario el consentimiento de la comunidad para cambiarlas hace que éstas se conviertan en un claro límite de la potestad real (Martínez Tapia 1998: 62) ${ }^{31}$.

30. Procede del lema tomista: El Derecho injusto no es Derecho y no debe ser obedecido. Así afirmarán estos autores:

Azpilcueta, Dictamen: «Toda orden, también la del monarca, contraria a la ley natural o divina, es injusta e ilícita».

Vázquez de Menchaca, Controvers., 45, n 6. "Quede en pie esta regala, que el príncipe está sujeto a las leyes, entendiendo esto en primer lugar, que está sujeto al Derecho natural».

Suárez, De legibus, 1. III, cap. XII.

31. De Rege, Lib. I. cap. 9. A diferencia de Bodino, pues éste habla también de Ley Fundamental, pero la entiende «como fundamento y legitimidad de ese poder único, exclusivo y 
Ahora bien, ¿¿debía el rey someterse a estas leyes? Es decir, ¿era el rey princeps legibus solutus o debía someterse al Derecho positivo? En su día, Santo Tomás de Aquino hizo una distinción entre vis directiva y vis coactiva. "El príncipe queda sujeto a la fuerza directiva u obligativa en conciencia de ley, pero no a la coactiva», mientras que los ciudadanos están sujetos a las dos (Martínez Tapia 1998: 63). En el siglo XVI muchos juristas y teólogos vinieron a defender que el príncipe estaba sometido a la ley, negando cualquier potestad que lo autorizase a obrar sin límite (Martínez Tapia 1998: 63) ${ }^{32}$. Ahora bien, si unos se ajustaron a la tradición tomista, otros, más radicales, fueron más allá, y exigieron en sus escritos el sometimiento de la autoridad a las dos. Suárez y Mariana, son partidarios de que las leyes fundamentales sí obligaban al monarca a su cumplimento moral y jurídico, mientras que las ordinarias «no le obligan de forma coercitiva, ya que sólo tienen para él un carácter meramente directivo» (Martínez Tapia 1998: 64-65).

Otra sujeción o límite del poder del príncipe es el Derecho privado. Es decir, estaba obligado civilmente a cumplir con los contratos firmados (66). Es más, al rey le correspondía la protección de los patrimonios particulares, a defender la propiedad privada, como afirman Molina o Mariana: «propiedad privada [...] e impuestos públicos son dos muros ante los que el rey tiene que detenerse y buscar, previamente, el consenso de los afectados» (69).

El príncipe debía estar sujeto también por los cuerpos representativos, las Cortes, en cuanto que éstas ostentaban la representación de la comunidad política, al mismo tiempo que controlaban el poder del príncipe mediante un conjunto de instrumentos como el reparo de agravios, el derecho de sobrecarta, o la fórmula castellana del «obedézcase pero no se cumpla» $(70)^{33}$. Finalmente, el Derecho de Gentes, sería contemplado como un límite jurídico externo.

Más ¿cuáles serían los límites teleológicos del poder del príncipe? El poder del príncipe es un officium, y como tal está obligado a cumplir unos fines, entre los que, por encima de todo, está el bien común (Martínez Tapia 1998: 73). Para Bartolomé de las Casas «las leyes están redactadas para el bien común de todos y no en perjuicio de la república», y, en consecuencia «todo lo que un

absoluto en que consiste la soberanía. Se trata, ciertamente, de leyes superiores al soberano que éste no puede derogar -referidas a la sucesión en la corona, es decir, al orden institucionalizado-, probablemente de origen consuetudinario y cuyo incumplimiento generaría, en todo caso, una sanción extrajurídica, de tipo político, pues los súbditos, a juicio de Bodino, carecen de derecho para sancionar al soberano que viola tanto las Leyes Fundamentales como el Derecho natural» (Martínez Tapia 1998: 61).

32. No así en el siglo XVII donde se acepta el principio de la no subordinación del príncipe a la ley. Y Maravall cita a Andrés Mendo, Castillo de Bobadilla, Jerónimo de Zeballos, Márquez, Tovar, Lancina, Portocarrero, Fernánez de Medrano, Mut, etc. (Maravall 1997: 206).

33. Sobre la protesta de Mariana, para que las Cortes recuperaran su papel Mariana, 1981: I, cap.8. También autores como Azpilcueta, Covarrubias, Suárez, Mariana o Rivadeneyra, resaltaron la necesidad del rey de contar con Consejos, no solo para pedir su opinión, sino para deliberar con ellos. 
gobernante haga en perjuicio de la totalidad del país contra el consentimiento y voluntad de sus ciudadanos lo hace contra el orden natural» (Martínez Morán, 1991: 430$)^{34}$.

\section{El derecho de resistencia y el tiranicidio}

Ahora bien, si el príncipe viola tanto estos límites jurídicos como teleológicos, ¿puede la comunidad política ejercer el derecho de resistencia? Bartolomé de las Casas es claro:

el que usa mal del dominio no es digno de señorear, y al tirano ninguna fe, ni obediencia ni ley se le debe guardar.

\section{Y concluye:}

tienen derecho los seńores de hacer la guerra contra el tirano y también tienen derecho los súbditos ${ }^{35}$.

Y lo podrá hacer, sostiene el Dr. Navarro «en aquellos casos en que los monarcas abusen de la potestad que se les concedió empleándola en la destrucción de sus propios estados o dirigiéndola a fin contrario de aquel para el que los pueblos se la concedieron o debieron concederla» (Bullón y Fernández 1936: 70-71 ${ }^{36}$. El mismo Azpilcueta escribía su Manual de Confesores, donde incluía un capítulo, el XXV, titulado: "De algunas preguntas particulares de algunos estados. Y primeramente del de los reyes y señores, que en esta vida no tienen superiores cuanto a lo temporal». ¿Cuándo peca el rey? Y uno de los epígrafes es claro:

Si no permitió que el pueblo libremente defendiese su bien público y sus libertades, que por derecho divino o fuero humano, mayormente jurando le conviene... (Azpilcueta 1567: 521).

En definitiva, el derecho de resistencia es consecuencia lógica de la concepción dual de la soberanía. Un derecho de resistencia que sería asumido por la mayoría de los miembros de la Escuela, que defiende el ius resistendi contra el tirano. Más ¿quién debería castigarle?

En líneas generales, y como resume Bullón, los autores distinguían entre dos tipos de tiranos: los que habían usurpado el poder (tyrannus ab origine); y aquellos que habían adquirido bien su poder pero lo ejercían de forma abusiva (tyrannus a regimine). En el primer caso, el intruso que se apoderaba del poder, cualquier ciudadano estaba facultado para darle muerte, sin necesidad de 
juicio y sin una autorización o delegación expresa de la colectividad (Bullón y Fernández 1936: 153-154) ${ }^{37}$.

En el segundo caso, cuando el gobernante es legítimo, pero realiza acciones indignas en contra del bien común hay división de opiniones. Unos consideran que aun a pesar de la legitimidad originaria del poder de un rey, al transformarse en tirano «no sólo se le puede y debe resistir, sino incluso destronarle y darle la muerte, siempre que esto se haga, no por la iniciativa privada de cualquier ciudadano, sino por resolución pública, es decir, por acuerdo expreso de calificadas y suficientes representaciones del país tiranizado». Entre estos se incluyen Báñez, Mariana, Molina y Suárez (Bullón y Fernández 1936: 161), aunque todos hablan de la necesidad de prudencia antes de llegar a caer en el tiranicidio.

Sí es cierto que Mariana da un paso más, pues aunque considera procedente el acuerdo público por los principales representantes, puede haber casos en que la tiranía sea tal, que al impedir toda vida jurídica, al ser imposible un acuerdo público, cualquier ciudadano puede libertar al pueblo, eliminando al déspota (Mariana 1981: cap. 6) ${ }^{38}$.

Ahora bien, es el mismo Mariana, el que matiza la utilidad del asesinato del tirano que hubiese llegado al trono por derecho hereditario o voluntad del pueblo:

Creemos que ha de sufrírsele, a pesar de sus livianidades y sus vicios, mientras no desprecie las leyes del deber y del honor a las que está sujeto por razón de su oficio. No se puede cambiar fácilmente de reyes si no queremos incurrir en mayores males y provocar disturbios.

Ante un rey que menospreciase las leyes y la religión había que "proceder con mesura»: primero había que amonestarlo. Pero si rechazara los consejos, si no hubiese esperanza de rectificación por su parte, el primer paso debería ser no reconocerle como rey. Esto, indudablemente, provocaría una guerra, y habría que prepararse para ello. «Y si fuera necesario, y no hubiera otro modo posible de salvar la patria, matar al príncipe como enemigo público, con la autoridad legítima del derecho de defensa ${ }^{39}$.

Ahora bien: ¿cumplía Enrique IV con el perfil de un tirano? Para Mariana sería tirano:

- el usurpador, quien «disfruta del poder no por sus méritos ni por concesión del pueblo sino por la fuerza, por la intriga o por las riquezas».

37. La doctrina como tal es sostenida por: Diego de Covarrubias, Epitome in quartum librum Decretalium (1545); Juan Ginés de Sepúlveda, De regno (1571), Domingo Báñez, De iure et iustitia decisiones (1594), Juan de Mariana, op. cit., cap. 6, Juan Márquez, Gobernador cristiano (1612), Lib. 1, cap. VIII, Francisco Suárez, Defensio fidei, cap. IV, libro VI, Luis de Molina, De Iustitia, tratado 3, disp. 6.

38. Citado por Bullón y Fernández (1936: 161-162).

39. Suárez también matiza: «Si la muerte del rey hubiera de causar la ruina del Estado o si a causa de ella hubiera de sufrir gravemente el bien común, la persona privada tiene el deber, por amor a la patria y al bien común, de no matar al rey, aunque esto ponga en inminente peligro su propia vida; pero este deber pertenece al orden de la caridad». Citado por Rommen (1951: 384). 
- Aquel, que si bien disfruta del poder por la voluntad del pueblo «lo ejerce con violencia y no lo acomoda a la utilidad pública, sino a sus placeres, a sus vicios o a su utilidad particular».

- Aquel que "para impedir que los ciudadanos se puedan sublevar, procura arruinarlos, imponiendo cada día nuevos tributos, sembrando pleitos entre los ciudadanos y enlazando una guerra con otra».

- Aquel que por miedo trata a sus ciudadanos como esclavos y «para evitar que estos preparen su muerte, suprime todas sus posibles garantías y defensas, les priva de las armas»

En definitiva tirano es aquel:

que subvierte todo el Estado, se apodera de todo por medios viles y sin respeto alguno a las leyes, porque estima que está exento de la ley. Y cuando se ocupa de los asuntos públicos, obra de tal manera que todos los ciudadanos se sienten oprimidos por toda clase de males con una vida miserable y los despoja de su patrimonio para dominar él solo en los destinos de todos (Mariana 1981: 66-69).

Difícilmente pudiera interpretarse la situación de la Francia de 1610, con la que se vivía en el clima de guerra civil y de guerra de religión de 1589. Todo apunta a que, desde un punto de vista español, en la teoría y en la práctica, esto no era así, en cuanto que según las relaciones y crónicas Enrique IV era un rey «legítimo» ${ }^{40}$ y admirado por su pueblo ${ }^{41}$. Es ilustrativo al respecto el texto de Novoa:

la melancolía y el humor diabólico de que estaba compuesto [Ravaillac], le hacía discurrir temerariamente y recibir todas las impresiones que le dictaba su fantasía, con que se dio a pensar si el rey era cristianísimo y legítimo de Francia, y si era pecado o no matar un tirano. Con estos pensamientos había ido y vuelto muchas veces de Angulema a París, y consultado con algunos religiosos el caso; los cuales le habían procurado disuadir dél por espacio de tres años en que había alimentado en su pecho el pensamiento de matar al rey (1875: I, 428).

Por otra parte, creo que es indudable, que el asesinato de Enrique IV pudo marcar un punto de inflexión en el pensamiento en torno al derecho de resistencia y al tiranicidio Es más, se advierte ya una tendencia, apuntada en su día por José Antonio Maravall, de un cambio en las otrora radicales actitudes hacia el tiranicidio, fruto, principalmente de las circunstancias históricas que se vivían.

40. Así lo resalta Quevedo:

Su herencia conquistó, por merecerla;

nació rey por la sangre que tenía;

por la que derramó, fue rey famoso. (1952: 520)

41. No así en la corte francesa en donde, como sabemos las tesis de Mariana (1599) pusieron en peligro la presencia de la Compañía en Francia, lo que dio lugar a que en 1610 el general de los jesuitas, Aquaviva, prohibiera a sus miembros la defensa del tiranicidio tal y como fue sostenida por el padre talaverano. Vid. Braun (2007: 8-10). 
Para autores como Covarrubias, Sepúlveda y sobre todo, Márquez, "por legitimidad de origen» debía respetarse la vida del príncipe, aunque deba resistirse a sus mandatos. Así dice Márquez en El gobernador cristiano... (1612):

la mayor y más sana parte de los doctores tiene por cierto que no es lícito atentar contra sus personas, porque mientras el príncipe retiene la suprema potestad, por derecho natural le deben obediencia los pueblos y no sólo no se les permite maquinar contra su vida, pero ni negarle la adoración y reverencia naturalmente debida a los superiores... Y engánanse torpemente los que se prometen sosiego por medio de la muerte del tirano, porque como decía Julio César, y está muy comprobado con experiencias, nunca los reinos se truecan sin grandes turbaciones y de no tolerar los príncipes insolentes se siguen mayores daños a las repúblicas. Por lo cual San Jerónimo cuenta entre las calamidades de su tiempo las muertes de algunos tiranos insufribles... Y es tanto más necesaria en estos tiempos esta doctrina cuanto más se va abriendo puerta en ellos a maquinar contra la seguridad de los príncipes, a que me admira no haber atendido los que siguen la contraria, porque si una vez se da licencia a la república para matar al tirano, ¿quién detendrá la rabia del pueblo a que no conspire contra su rey por livianas ocasiones y dé nombre de tiranía a la ejecución rigurosa, al tributo levantado, y a otras órdenes en que por ventura habrá entrado el Príncipe contra su deseo y a pura necesidad, como se dice del rey don Pedro de Castilla, a quien el gran número de justicias, al parecer de muchos necesarias, dio nombre de cruel en el lenguaje del vulgo? [...] Lloró con entrambos ojos el reino de Francia, la de Henrico III que, so color de restaurar la libertad pública, mató un fraile de una puñada el año de mily quinientos ochenta y nueve, porque se siguieron de ella las guerras civiles que la molestaron hasta la reconciliación de Henrico IV, que este mayo de seiscientos y diez murió también a manos de un plebeyo, casos verdaderamente atroces y siglo (dijo no sé quién) sangriento en la paz, no sólo cruel en la guerra. En veinte años ha visto Francia dos principes muertos a hierro, inhumanidad no oida entre cristianos, y contra quien siempre se armarán las plumas de nuestros historiadores... (1949: 78-79) ${ }^{42}$.

\section{Y así afirmará Quevedo en su Marco Bruto:}

Grave delito es dar muerte a cualquier hombre, más darle al rey es maldad execrable, y traición nefanda no solo poner en él las manos, sino hablar de su persona con poca reverencia o pensar de sus acciones con poco respecto. El rey bueno se ha de amar, el malo se ha de sufrir. Consiente Dios el tirano, siendo quien le puede castigar y deponer ¿y no le consentirá el vasallo, que debe obedecerle? No necesita el brazo de Dios de nuestros puñales, para sus castigos, ni de nuestras manos para sus venganzas (Citado por Maravall 1997: 406-407).

\section{CONCLUSIONES}

En definitiva, la muerte de Enrique IV, fue rápidamente divulgada como una muerte alevosa cometida por un traidor contra un monarca que, a pesar de ser el principal enemigo de la nueva política internacional española, fue admirado por su valor militar. Es más, Felipe III y su corte, fueron los primeros en lamentar una pérdida injustificable, aunque no por ello fue dejada de ver con alivio, ante la amenaza creciente de una guerra que, de ser un hecho local, podría

42. El subrayado es nuestro. Vid. también Bullón y Fernández 1936: 159-161. 
haber dado lugar al estallido de un período de enfrentamiento generalizado en toda Europa. Cabe interpretar, por otra parte, que para la mayoría de los autores, aquello respondía más a las características de un regicidio que en vano podría encontrar sustento inspirador en las tesis del derecho de resistencia y del tiranicidio de la Escuela Jurídica Española, por más que la corte francesa -condena de la Sorbona el 4 de junio de 1610, sentencia del Parlamento de 8 de junio (Mousnier 1964: 212)- lo interpretara así y llevara a poner en entredicho a la Compañía de Jesús y a autores como Mariana, solo salvada in extremis por el general Acquaviva.

\section{Bibliografía}

Azpilcueta Martín de, Manual de confesores y penitentes, que contiene quasi todas las dudas que en las confesiones suelen ocurrir de los pecados, absoluciones, restituciones, censuras \& irregularidades, Barcelona, Claudio Bornat, 1567, 799 p.

Ballesteros Gaibrois Manuel, El padre Juan de Mariana. La vida de un sabio, Barcelona, Amaltea, 1943, 258 p.

Bercé Yves-Marie, Fasano Elena (eds.), Complots et conjurations dans l'Europe Moderne, Roma, École Française de Rome, 1996, 773 p.

Braun Harald E., Juan de Mariana and Early Modern Spanish Political Thought, Aldershot, Ashgate, 2007, 200 p.

Brufau Jaime, El pensamiento político de Domingo de Soto y su concepción del poder, Salamanca, Universidad de Salamanca, 1960, 250 p.

Bullón y Fernández Eloy, El concepto de la soberanía en la Escuela jurídica española del siglo XVI, Madrid, Librería General de Victoriano Suárez, 1936, 223 p.

Cabrera de Córdoba Luis, Relaciones de las cosas sucedidas en la Corte de España desde 1599 hasta 1614, Madrid, Imprenta de J. Martín Alegría, 1857, 655 p.

Carrillo Martín, Anales cronológicos del mundo, Zaragoza, Hospital Real y General de Nuestra Señora de Gracia, 1634, 525 h.

Centenera Sánchez-Seco Fernando, «¿Defiende Juan de Mariana al monje que terminó con la vida del rey Enrique III de Francia?», Torre de los Lujanes, 2004, 54, pp. 87104.

Céspedes y Meneses Gonzalo de, Primera parte de la historia de D. Felipe el IIII, rey de las Españas, Lisboa, Pedro Craesbeeck, 1631.

Courouau Jean-François, «Dos poemas en castellano para el nacimiento y la muerte de Enrique III de Navarra y IV de Francia», Principe de Viana, 2004, 65, pp. 623-638.

García Bernal José J., «Leer Relaciones de Solemnidades en el Siglo XVII: Entre la Educación Cortesana y el Placer de la Maravilla» en Relaciones de Sucesos en la Biblioteca de la Universidad de Sevilla, Sevilla, Universidad de Sevilla, 2008, Vol. 1, pp. $95-116$.

Góngora Luis de, Obras completas, ed. J. Millé y Giménez - I. Millé y Giménez, Madrid, Aguilar, 1972, $1293 \mathrm{p}$.

González Dávila Gil, Historia de la vida y hechos del inclito monarca, amado y santo D. Felipe tercero, Madrid, Fundación Histórica Tavera. Digibis, 1998.

Guadalajara y Javier Marcos de, Quinta parte de la historia pontifical, Barcelona, Sebastián Cormellas, 1630, 584 p.

Mathieu Pierre, Historia de la muerte de Enrico el Grande, Cuarto rey de Francia deste nombre, escrita en francés por Pedro Mateo, Madrid, Diego Flamenco, 1625, $97 \mathrm{f}$. 
Jauralde Pablo, Francisco de Quevedo (1580-1645), Madrid, Castalia, 1999, 969 p.

Kamen Henry, Felipe de España, Madrid, Siglo XXI, 1997, 364 p.

Mariana Juan de, La dignidad real y la educación del rey (De Rege et Regis Institutione), ed. L. Sánchez Agesta, Madrid, Centro de Estudios Constitucionales, 1981, 481 p.

Maravall José Antonio, Teoría del Estado en España en el siglo XVII, Madrid, Centro de Estudios Constitucionales, 1997, 423 p.

Márquez Juan, Antología, ed. M. Cardenal de Iracheta, Madrid, Editora Nacional, $1949,166 \mathrm{p}$.

Martinengo Alessandro, «Dos muertes paralelas, Julio César y Enrique IV de Francia (el modelo de Plutarco de Pierre Mathieu a Quevedo)» en Roncero, V. y Duarte, J. E. (eds.), Quevedo y la crítica a finales del siglo XX (1975-2000). Vol 2, Pamplona, Eunsa, 2002-2003, pp. 145-164.

Martínez Morán Narciso, "Aportaciones del pensamiento español de los siglos XVI y XVII al derecho internacional y a los derechos humanos: su influencia en los problemas del mundo contemporáneo», Diálogo filosófico, 1991, 7, pp. 388-442.

Martínez Tapia Ramón, «Derecho y poder en el pensamiento jurídico español del siglo XVI. El problema de los límites del poder», Pensamiento, 1998, 54, pp. 45-83.

Mousnier Roland, L'assassinat d'Henri IV: 14 mai 1610, Paris, Gallimard, 1964, 410 p.

Novoa Matías de, Memorias de Matías de Novoa. Primera parte hasta ahora conocida bajo el título de "Historia de Felipe III por Bernabé de Vivanco», Madrid, Imprenta de Miguel Ginesta, 1875, vol. I, 555 p.

Quevedo Francisco de, Obras completas. Obras en verso, ed. L. Astrana Marín, Madrid, Aguilar, 1952, 1842 p.

Relacion verdadera, sacada de una carta de las que a Su Majestad enviaron, en que trata la muerte lastimosa del Quarto rey don Enrique de Francia y la jura de la reina y delfin su hijo despues de este triste suceso y del aprieto en que se vio el embajador de España con los sentimientos que los católicos reyes de España hicieron, Valladolid, Ana Vélez de Salcedo, 1610.

Relacion verdadera del solenissimo Acompanamiento, y particulares Ceremonias del entierro de Enrique Quarto, Rey de Francia, que duro tres dias desde veynte y nueve de Iunio hasta primero de Iulio que quedo el Cuerpo en San Dionys. Y vltimamente la aclamacion del Pueblo al nuevo Rey Luys Tercero deste nombre, Sevilla, Viuda de Alonso de la Barrera, 1610.

Ranum Orest, "The French Ritual of Tyrannicide in the Late Sixteenth Century», Sixteenth Century Journal, 1980, 11-1, pp. 63-82.

Rommen Heinrich A., La teoría del Estado y de la comunidad internacional en Francisco Suárez, Buenos Aires, Facultad de derecho y ciencias sociales, Instituto de Derecho Internacional, 1951, 523 p.

Scorraille Raúl de, El P. Francisco Suárez de la Compañia de Jesús, según su cartas, sus demás escritos inéditos y crecido número de documentos nuevos. II. El Doctor. El Religioso, Barcelona, Subirana, 1917, 525 p.

Usunáriz Jesús M., "Tiranicidio y derecho de resistencia en la Europa de los siglos XVI y XVII» en Vázquez de Prada M. (ed.), Terrorismo y magnicidio en la Historia, Pamplona, Eunsa, 2008, pp. 93-134.

Vázquez de Prada, Valentín, Felipe II y Francia (1559-1598). Política, religión y razón de Estado, Pamplona, Eunsa, 2004, 517 p.

Verissima relacion de las fiestas que se hizieron en la coronacion de la Reyna de Francia en Paris y orden con que todo se hizo. Assi mismo se dà quenta de la muerte del Rey de Francia, como sucedió, y en que forma, Sevilla, Bartolomé Gómez, 1610. 
